\title{
WHERE'S ALL THE 'GOOD' SPORTS JOURNALISM? Sports Media Research, the Sociology of Sport, and the Question of Quality Sports Reporting
}

\section{INTRODUCTION}

Across newsrooms and journalism schools, questions as to what constitutes or 'counts' as excellent reporting are currently inciting much debate. This in itself is not newsworthy: questions relating to quality, accountability, and public service have surrounded communications technologies since the invention of the printing press, and newspapers have proved to be no exception over the past 150 years. But media scholars such as Robert McChesney (2013) and Justin Lewis (2014) have recently argued that the present moment demands an intensified and deepened engagement with these questions, and the concerns that inspire them. Apprehensions inherited from the late $19^{\text {th }}$ and $20^{\text {th }}$ centuries endure about the centralization of mainstream media ownership, the influence of profit motives on the types of news stories that are offered to the public, a lack of diverse perspectives offered by journalists on key issues, and decreased funding and support for indepth investigative reporting. Additional concerns have also emerged about the viability of traditional models of revenue generation for major news outlets in an age of multimedia platforms - as individual stories are increasingly assessed according to the number of 'hits' and clicks they receive in online formats, and less according to the reputation of news outlets, or standards of journalistic excellence (McChesney, 2013). While these and related developments may well pose opportunities as well as challenges when it comes to 'quality' reporting, taken together they are mostly seen to undermine attempts to uphold any kind of agreed upon standard for excellence (Lewis, 2014).

Within these discussions of journalistic excellence, sports journalism is scarcely mentioned. For example, recent attempts to quantify, qualify and support different forms of 'excellent' journalism - including initiatives to develop frameworks for 'civic journalism’ (Rosen, 2001), 'deliberative journalism’ (Romano, 
2010), 'peace journalism’ (Lynch, \& McGoldrick, 2005), and 'development journalism’ (Thussu, 2000) seldom include references to sport or sports coverage. Possible explanations for this omission will be familiar to sports media scholars, with the most obvious relating to the long-standing reputation of sports journalism as the 'toy department' or 'sandbox' of the newsroom (Rowe, 2007). This reputation is at least partly attributable to the inherent ethical contradictions that sports journalists are known to face as they attempt to, on one hand, 'objectively' and 'impartially' report sport-related news, and on the other hand, offer an important promotional service for the sports leagues and events that they cover.

Nevertheless, there are reasons why we might expect sport to be afforded greater attention in this regard, not least its heightened significance in the economy of $21^{\text {st }}$ century news media industries. These developments have led Farrington et al. to claim that "sports journalism has moved from the toy department to the finance department," where "it is now seen as crucial to the incomes and audiences of many media organizations" (Farrington, Kilvington, Price and Saeed, 2012: 1). Such a claim does not in itself inspire questions or answers about 'quality' sports journalism: indeed, it might be more likely to incite skepticism as to what constitutes quality when the higher profile of sports content has coincided with clicks and hits becoming the currency of news media companies. Yet from a sociological perspective this would seem like an opportune moment to weigh in on how changes in the political economy of media industries could, do, and should be weighed against questions of quality sports reporting.

Impelled by these debates and developments, we have set out to ask the question denoted by our title: “where's all the good sports journalism?” More specifically, and with sports journalism conspicuous (to us at least) in its absence in the literature on journalistic quality, we have directed this question inward toward sports media research - and to the sociology of sport in particular. To be sure, this is not an obvious corollary to our eponymous question, and we have debated among ourselves and with colleagues whether the sociology of 
sport has the purview and expertise necessary to offer an account of quality sports journalism. After all, there are many sources of authority on sports media and journalism, including the field of sports communications, sports journalism schools, and of course, reporters themselves (Wenner, 2013). What's more, we have not questioned sociologists of sport directly - not in the essay to follow anyway. Instead, we undertook an analysis of leading sociology-related sports journals over the past five decades to assess what this body of knowledge has said about quality and 'best practice' sports coverage. That this is an unsolicited question posed in retrospect - and why sociologists of sport might be disinclined to offer 'best practice' advocations to journalists by virtue of particular disciplinary and political leanings - is the subject of much of our analysis.

Notwithstanding questions about the validity of our approach, we maintain that there are a range of compelling reasons for focusing on the sociology of sport's collective account of journalistic quality. The first reason emerged for us as we reviewed a set of recently published textbooks, manuals and how-to-guides about the practice of sports journalism written to educate aspiring sports journalists (Authors, 2015; see, for recent examples of texts, Andrews, 2015; Farrington et al, 2012; Gisoldi, 2011; Schultz, 2005; Steen, 2015; Toney, 2013). These books, authored either by sports journalists turned university educators or featuring collaborations between sports media scholars and current or former reporters, are practical guides to 'doing' sports journalism - rooted in anecdotes, experiences, and tales from the field. To varying extents, these texts also navigate the challenges that sports journalists face when covering social issues in which sport is implicated. Putting aside for the moment any evaluation of the advocations for covering social issues offered in these books, the fact of their publication in the first place, and their often collaborative authorship across journalism and academe, suggest that the question of quality in sports journalism - according to both academics and journalists, and in terms of covering topics that are in many cases the central focus of research by sociologists of sport - is a timely one. This point is buttressed by Hardin et al.'s finding that such texts would be improved if greater 
attention was paid to 'how to cover social issues' - with Hardin et al. noting in particular that the books they examined "do not encourage aspiring journalists to address gender inequities in sports journalism" (Hardin et al., 2006: 429).

Further support for our approach comes from 'radical' sports journalist Dave Zirin, who has suggested that sociologists of sport 'get off the bench' and begin to comment directly on sport-related social issues (quoted in C.R. King, 2008). While Zirin was in effect echoing calls for 'public sociology' among sociologists of sport, his comments also prompt the question of how sociologists of sport have - or have not - identified, theorized or promoted excellent journalist practice. The imperative for such questions was further highlighted within a set of recent articles in (among other venues) the Huffington Post and Washington Post - articles that reflected on one particularly controversial article that appeared on the sports journalism website SB Nation (i.e., Sports Blog Nation - a website that shares content with mainstream outlets like USA Today and CBS Sports). The article in question was described as offering a "highly-sympathetic profile of former Oklahoma City police officer [and college football player] Daniel Holtzclaw, a serial rapist who was sentenced to 263 years in prison last month for raping 8 women" (Kaplan, 2016), and inspired a range of commentaries about why the story was poorly written, to say the least, and how 'better' sports-related journalism should be done. Once again, given that sociologists of sport have written a great deal about violence, gender and media (see Bruce, 2015), we saw value in surveying whether and what kind of advocations for better coverage of such instances had been made within the literature.

Finally, in undertaking this study we were already aware of certain contributions to debates about quality from within the sociology of sport. For example, Peter Donnelly’s (2011) Taking Sports Seriously which collates what Donnelly sees as a selection of 'best of' journalistic articles is now in its $3^{\text {rd }}$ edition. Elsewhere, the work of scholars such as Jules Boykoff, Welch Suggs, and affiliates of The Tucker Center for 
Research on Girls and Women in Sport, like Nicole Lavoi, Mary Jo Kane and Cheryl Cooky - crosses the journalism-academic divide through their direct contributions to mainstream media coverage of sport-related social issues. The Denmark-based organization 'Play the Game' also champions collaborative and international relationships between critical sport scholars of all backgrounds (including a number of sociologists) and sports journalists who address sport-related social issues.

Our study is therefore driven by the conviction that sociologists of sport can contribute something to discussions of journalistic quality on issues like these, and is intended to catalyze debate about what that something might be. Put another way, we focus on the sociology of sport because contributors to that field have made immense contributions, spanning some fifty years, to thinking about the range of problems with sport-related media (Wenner, 2013). Reflecting on the strengths and range of these critical contributions, it seemed to us timely, if not belated, to put an alternate 'lens' on these sociological studies of sports journalism, focusing on the kinds of 'best practice' suggestions that have been made in these critical studies towards improving sports journalism. We thereby see our project as a response to a turn in sociology more broadly towards an understanding of what 'real Utopias' within society look like (Olin Wright, 2010), or could look like - with our approach focused especially on the strands of writing within the sociology of sport where 'best practice' has been addressed.

To begin addressing the questions of 'what counts as quality sports journalism,' and 'what do sociologists of sport think it looks like?' we consider, first, in our literature review, how journalistic excellence has been discussed and debated both outside and within sport studies-related fields in recent years. This involves departing from our sampled journals to highlight instances where leading sports media scholars have discussed matters of quality coverage. Next, we discuss our research methods and, in turn, present an analysis of all scholarly articles focused on sports journalism that have been published in eight major sociology-related 
sport studies journals, from their respective first issues, up to and including September 2016. We sought out instances where authors offered examples of and/or specific and clear advocations for a particular form of 'better', or what we might think of as 'best practice' journalism. One of the main findings that we will report is that commentary in these journals on what counts as good sports journalism is scarce, and that the remarks that are offered tend to be undeveloped, and in some cases contradictory. While this is significant in its own right, most of our subsequent discussion is a reflection on the possible explanations for this scarcity and the issues it raises. These surround, for instance: the delineation and mission of the sociology of sport as a field of academic inquiry; the relationship between the sociology of sport field and other fields concerned with sports journalism and media, such as sport communication, sport management, and sport journalism itself; the relationship between the sociology of sport and sports journalism as industry; and the public reach and assumed responsibility of the sociology of sport field. Concluding comments then offer some considerations and possible lines of inquiry for research that seeks out and aims to theorize and even influence sports media.

A final note before beginning our review of debates about 'quality' journalism: while we have focused on the sociology of sport both in our sampling and in our chosen venue for publication, our aim is not to police or reinforce the boundaries between scholarly fields. Such delineations are perhaps not possible even if they were desirable, as the sociology of sport is just one of many fields of study concerned with sports journalism and sport media (Wenner, 2013). Moreover, some of the contributors to the journals and articles included within our analysis are former or current journalists; some work across different fields of inquiry, including the sociology of sport, while others do not primarily write about sport, or media. Something similar is true of the journals we have selected for analysis: Even those whose titles proclaim a sociological focus, such as the IRSS, do not insist on a single disciplinary influence in terms of article content or contributors' expertise. Rather than work towards identifying the single most apposite disciplinary or professional venue from which 
to debate and decide on matters of quality sports reporting, our aim is to contribute to a generative project that moves beyond the borders of fields, disciplines and vocations: a project that draws attention to a question that we found to be understudied in sociological scholarship concerning sports media and journalism, and that, at the height of our ambition, may lead sociologists of sport and others who hold interest and expertise in sports journalism to engage with sports journalists and sports media educators in more complementary and collaborative ways.

\section{REVIEW OF LITERATURE}

\section{Journalism, Democracy and Quality: Evaluating Journalism}

Matters of 'best practice' have perennially been of import in journalism insofar as they implicate the purportedly democratic and public mandate of media institutions. Yet, amid the fluctuating political economy of journalism and media industries in the twenty first century, such questions have recently become objects of professional and scholarly inquiry that, in turn, warrant the attention of sports media scholars.

A primary example is the criteria used in the ranking of articles that are assessed for journalistic awards (Shapiro et al., 2006), and studies using survey tools to gather information from newspaper editors and reporters about their views on the topic (Kim and Meyer, 2005). In these and other studies, a variety of evaluative criteria have been put forwards. Deuze (2005), for example, notes that better quality journalism is commonly thought to be 'objective' and 'timely', to have a 'public service component', to be 'autonomous' (i.e., done by those who were free from conflict-of-interest), and to be guided by a well-defined and well-thought-out code of ethics (pp. 445-447). Shapiro, in his comprehensive review of research on the topic, indicates that 'best practice' journalism is often associated with:

...independent observation; efforts to ensure accuracy; openness to appraisal (enabling the audience to

identify and assess sources of information and opinions); editing (the work is part of an unfolding 
account to which others contribute); and presentation that is uncensored by sources, owners, advertisers, and others (p. 559, cf., Shapiro, 2010).

Shapiro further suggests that the following quotation - from Bogart (2004) - is an 'especially concise' summary of the criteria commonly associated with journalistic quality:

When experienced news people are asked what makes for quality, a number of words and phrases inevitably surface: integrity, fairness, balance, accuracy, comprehensiveness, diligence of discovery, authority, breadth of coverage, variety of content, reflection of the entire home community, vivid writing, attractive makeup, packaging or appearance, and easy navigability (Bogart, 2004: 40, quoted in Shapiro, 2010: 148).

Shapiro (2010) supplements Bogart's list of criteria by identifying "benefit to society" as a characteristic of quality journalism (p. 148).

Shapiro's "benefit to society" argument has been taken up in a range of ways by those promoting an array of alternative, 'values-driven' forms of journalism - including public journalism (Rosen, 2001), participatory journalism (Singer et al., 2011), development journalism (Thussu, 2000), and peace journalism (Lynch and McGoldrick, 2005). While proponents of these approaches have a range of views on what counts as 'better' reporting, what they share is a belief in the idea that criteria and guidelines pertaining to news contents and the process of reporting can help journalists make more tangible and positive contributions to democracy, peace, development and so forth (Cottle, 2006).

There are of course still questions and debates about how well the assumptions underpinning some of these forms of journalism align with classical understandings of 'excellent' journalism, as articulated by those working in traditional news outlets - noting that those doing journalistic work that is intended to be, for example, 'peace-promoting' are sometimes criticized for lacking the sort of 'objectivity' that many journalists 
champion (Lynch, 2012), while others have reservations about the use of normative criteria for something as context-dependent as journalistic writing (Nohrstedt \& Ottosen, 2011).

While much more could be said here about these debates, what we will emphasize is that there are many ambiguities and tensions associated with defining 'excellent journalism', and that ongoing discussions are taking place in academia and within the journalism profession that are intended to clarify some of these issues. We also suggest, following Shapiro (2014) and others, that if a goal of studying and critiquing journalism is to create some form of positive change, then there is value in identifying what 'best practices' look like, and exploring why and under what circumstances these would be considered best practices - even while acknowledging that there is not a single 'formula' for excellent journalism. Put simply, without at least attempting to offer guidelines for what constitutes 'excellent journalism' (beyond identifying what 'bad journalism' is), why would we expect to see tangible and positive changes in journalistic process or content production?

\section{Evaluating Sports Journalism}

The materials we reviewed in the previous section included no information that we could find about sports journalism. This apparent scarcity of research on what counts as 'quality' or 'excellent' sports journalism was a main reason we decided to systematically look for commentary on the topic in a range of sociology of sport-related academic journals. We of course acknowledge that the study of sociology of sport-related journals included in our analysis below does not capture all of the sociological work on this topic. Recognizing this, we discuss in this section some key themes that emerged from our review of articles and/or books that fell outside our sample that offer important context and introductory insights into the question of 'quality' sports journalism. We refer to some other books and articles like these in our Discussions section as well. This review is selective in the sense that our focus is on key texts, articles and passages that focus especially on what counts 
as 'quality' sports journalism - with the idea that our study itself will pick-up on how much and how well the sociology of sport field has done in explicitly defining 'quality' from a sociological perspective.

An obvious starting point here is Raymond Boyle's (2006) book Sports Journalism: Context and Issues, a rigorous exploration of the sport journalism profession that includes an assortment of references to 'quality' or 'excellence' in sports journalism. Terms, phrases and descriptions that appear throughout the book that speak to journalistic quality include: impartiality and neutrality (p. 18), 'serious' and 'literary' journalism (p. 20), 'speaking the truth' (p. 23), demonstrating in-depth knowledge of the sport being covered (i.e., "knowing the game”) (p. 22), 'critical' journalism (p. 55), balanced and objective journalism (p. 56), effective storytelling (p. 69), “investigative and uncomplicit” journalism (p. 71), “critical investigative” journalism (pp. 96-97) and "public service journalism" (p. 95). While Boyle recognizes that the meanings of each of these terms, phrases and descriptions are not necessarily self-evident - and that these terms are the ones most commonly used by sports journalists themselves when discussing journalistic excellence - he is understandably selective when it comes to discussing the nuances and problems with each. For our purposes, one of the more useful elaborations he offers is of "public service journalism." This is the sort of journalism that sociologists of sport would seem to be especially concerned about since it implies a concern with civic issues and inequality. In this case, Boyle equates public service journalism with investigative journalism - which he describes as in-depth journalism that goes 'behind the scenes' and 'exposes wrongdoing' (p. 95). We engage more directly with some of these concepts in our own discussion of findings, later in this paper.

In his book and elsewhere, Boyle draws heavily on the work of another influential figure in the sociological study of sport journalism, David Rowe. Included in Rowe's body of writing is a typology he devised to describe four different forms of sports journalism (Rowe, 1992). These are: hard news, soft news, orthodox rhetoric and reflexive analysis. Reflexive analysis - also a term that would seem to have particular 
relevance for sociologists of sport interested in socially-relevant journalism - refers to "[journalism] which places the sports journalist at the centre of wider political, economic and cultural factors and influences, and is traditionally most likely to appear either outside of the sports pages or in small doses in the broadsheet press" (Boyle, 2006: 28). 'Reflexive' in this case would seem to equate with the more context-sensitive journalism that Boyle describes as 'critical' journalism.

Complementing Boyle's research, Rowe's work includes additional discussions about what quality sports journalism looks like, and the extent to which it exists. He speaks to these issues directly in the following quotation from a 2007 article that discusses the status of sports journalism in the field of journalism more broadly. He is referring in the following statement to findings from the Australian component of an international survey intended to better understand the 'state of journalism':

[E]vidence from the survey elicited from the Australian context has provided little to counter accusations that sports journalists exist in in a fairly cosy world with limited horizons, and that they are likely to leave sustained, critical inquiry into sport and its relationship with other major areas of society and culture, to others - including journalists from other disciplines... There seems to be little concern with problems beyond the daily sports round, a narrow range of themes addressed (Rowe, 2007: 399). Rowe refers in the same article to his goal of assessing the extent to which sports journalists were "engaged in the investigation, analysis and critique that is the legitimate purpose of 'news culture" (p. 386) what Rowe also referred to as "critical investigation" (p. 386). Although Rowe speaks cynically about the state of sports journalism in Australia in this instance, the point we emphasize here is that 'excellent' or 'socially engaged' journalism was described by Rowe as 'problem-oriented journalism.” For the purposes of the survey Rowe alludes to, "problem-oriented journalism" denotes journalism that is "critical' and engaged journalism as opposed to "depoliticized" journalism (p. 389). 
Rowe's foundational 1999 book Sport, Culture and the Media: The Unruly Trinity includes additional references to what critical sociologists might consider 'quality' journalism. For example, Rowe described the value some sports journalists (and most news journalists) place on providing "analysis and interpretation of complex problems" and "taking the role of sceptical 'adversary' in dealing with public officials and businesses" (p. 48) - characteristics that are reminiscent of public service and investigative journalism referred to in Boyle's research. Rowe's research also revealed that the more revered sports journalists are thought (by other sports journalists) to be "capable of reaching beyond sport into the more universal and profound sphere of individual motivation, the 'human condition', the state of society and so on" (p. 59). Rowe goes on to suggest that for these especially capable sports journalists, "sports reporting becomes first sports writing, and then writing which uses sport as a vehicle for the exploration of wider subjects and themes rather than being 'consumed' by it" (p. 59).

Oates and Pauly (2007) take up this theme when they describe what has been called the 'New Journalism' that emerged in the 1960s. The New Journalists - including authors like Norman Mailor, Tom Wolfe, and Gay Talese - offered "fresh" and "sophisticated storytelling" about popular culture and society, and "saw sports contests and characters as a sociologically rich domain worthy of their [the New Journalists] best craft" (Oates and Pauly, 2007: 340). Oates and Pauly refer to writing about the social and cultural relevance of Muhammad Ali (a common topic at the time) as an example of this. Oates and Pauly finally point to the tendency of more critically-oriented New Journalists to "undermine older narratives of sport as heroic or epic" (p. 342).

While in this instance Oates and Pauly are describing the sort of journalism that sociologists of sport might see as desirable - i.e., critical and sociologically-inspired writing - they also point out that "because such writing [presently] remains at the margins of journalistic practice, we [i.e., meaning critics of journalistic 
practice] do not subject it [i.e., sports journalism] to the rigorous ethical criticism we more normally direct at other forms of reporting, except to stigmatize [sports journalism] as an obviously defective practice that proves the worth of normal journalism" (p. 343). Oates and Pauly's observation is intriguing in the sense that it picks up on the idea that sports journalism is commonly the subject of offhanded critique - but is rarely examined with balanced attention to both the problems and strengths of particular forms of sports writing.

Their observation also refers to the role that journalistic ethics might play in helping journalists of all backgrounds set out guidelines for a form of excellent practice. Along with Oates and Pauly, sport scholars like MacNeill (1998) and Horky and Stelzner (2013) have discussed ethics in sports journalism in relation to 'quality' sports journalism. While the usual focus of discussions in this context is on the problem of 'complicit reporting' - meaning that reporters who need access to athletes, teams, and leagues in order to write stories will sometimes avoid critical investigative work in order to maintain the positive relationships that are needed to ensure access - MacNeill (1998) also noted that the pressures on sports journalists to break controversial stories about high profile athletes has also led to the opposite situation, where the rights of athletes to privacy may be compromised as journalists pursue sensationalist angles and sometimes unfairly amplify athlete-related scandals. As a response to this issue, MacNeill refers readers to McPherson et al.'s (1989) outline of responsibilities that sports journalists should be living up to, including "making sound decisions as gatekeepers of information, to present appropriate news rather than 'smut' and 'irrelevant' information; to avoid muckraking in order to increase sales; to report fairly and accurately; and to offer hard evidence for criticisms about sport” (McPherson et al, 1989: 163, quoted in MacNeill, 1998: 104).

Horky and Stelzner (2013) offer their own list of principles associated with 'quality' journalism that they adapted from a set of ethical guidelines recently devised by the Association of German Sports Journalists. The list includes the following: 
- avoid nationalistic and chauvinistic writing - and "avoid racial, religious or political defamation or discrimination" (Verband Deutscher Sportjournalten, 2010: 1, quoted in Horky and Stelzer, 2013: 126)

- to champion a humane, doping- and corruption-free sporting environment

- to "protect their journalistic impartiality and turn down gifts that could undermine their independent status" (Verband Deutscher Sportjournalten, 2010: 1, quoted in Horky and Stelzer, 2013: 126)

- to consider consequences of reporting on individuals' lives

- thoroughly researching articles, reporting truthfully and objectively - using accurate citation and unambiguous language

- "transparent in criticism of others" (Verband Deutscher Sportjournalten, 2010: 1, quoted in Horky and Stelzer, 2013: 126)

Although recommendations like these are obviously useful when it comes to thinking about what (more) ethical journalism could look like, MacNeill (1998) is careful to point out that ethical guidelines are always context-dependent and will shift over time - just as societal and cultural norms shift over time. Such guidelines are also informed by and responded to according to the incentive systems reporters work within, as well as personal codes. As Toulmin (1986) put it, journalistic ethics, on a practical level, are "socially informed pragmatism" (p. xvi, quoted in MacNeill, 1998: 105).

In sum, there exists of body of writing by scholars who work across the sociology of sport, sport communication and sports journalism that includes reflections on what counts as 'good' sports journalism. While we have highlighted in this review some of the key themes pertaining to quality offered by some sport scholars, we recognize that there are other relevant sociological studies published in venues not explicitly associated with the sociology of sport - venues like Mass Communication \& Society, Journalism and Mass 
Communication Quarterly, Journalism, Newspaper Research Journal, and the Journal of Sports Media. Articles in publications like these by scholars like Marie Hardin, Erin Whiteside, Lawrence Wenner, Andrew Billings, Welch Suggs, Sada Reed, Jimmy Sanderson, Jeffrey Kassing, and T.C. Corrigan - who work deftly across the disciplines of journalism, communication, and sociology in their research on sports journalism include discussions of, for example, ethical norms and practices in sports journalism when it comes to coverage of topics like Title IX (see, for example, Hardin et al., 2007) and on broader topics pertaining professionalism (e.g., Suggs, 2015).

Furthermore, we acknowledge that the bourgeoning field of 'communication and sport' deserves particular recognition here, if not in-depth attention in this specific context. This field is integrally linked with the sociology of sport in terms of the scholars who contribute to it and the approaches to research adopted by many working within it. Our inclusion of the journals Communication \& Sport and the International Journal of Sport Communication in our sample of sociology of sport-related journals we chose for analysis in the study reported below is an attempt to recognize this overlap in our study. We also highlight here - in addition to the range of journals and scholars noted above - Paul Pederson's edited Routledge Handbook of Communication (2013), that includes an impressive range of articles that speak often to journalism-related topics.

With this background, our study, outlined below, was designed to fill gap in thinking about how the sociology of sport field especially has contributed, and might contribute further, to broader discussions about quality sport journalism - while hopefully inspiring discussion about how related sub-fields (e.g., sport communication) concerned with quality sport journalism have responded to similar questions.

\section{METHODS}

\section{Sampling, Definitions and Procedures}


To pursue our goal of examining the types of suggestions that have been offered for journalistic 'best practice' by those who publish in sociology of sport-related journals and 'how much' has been said about the topic, we first delimited our research to journal articles pertaining to 'sports journalism' broadly defined. We did this by studying research articles that examined coverage of and/or reporting on sport published in eight major English speaking titles that publish sociological studies of sport. ${ }^{1}$ These journals are: Journal of Sport \& Social Issues (JSSI); International Review for the Sociology of Sport (IRSS); Soccer \& Society (S\&S); International Journal of Sport Communication (IJSC); OLYMPIKA (OL); Sociology of Sport Journal (SSJ); Sport in Society (SinS); and Communication and Sport (CS). As noted earlier, a number of relevant research articles, as well as chapters and monographs, fall outside of these titles, and our literature review and discussion attempt to account for some of this material. Of course there will still be material published elsewhere - in non-sports journals and media-focused edited collections, for instance - that escape our sample. Notwithstanding these omissions, we suggest that the research featured in these journals still offers a strong indication of how the field has collectively approached the question of 'excellent' or quality sports journalism over time - and the extent to which those writing in these journals included advocations for 'best practice'. Put another way, the intent is not to pick up on all advocations that have been offered by any author, in any field but, instead, to get a sense of what those writing in the sociology of sport field have said about 'quality' sports journalism - and, in turn, what might be said about the sociology of sport field from these findings.

We consulted each issue of the eight journal titles, from their respective founding issues up until September 2016, initially to ascertain all articles concerning sports media coverage. ${ }^{2}$ This was a manual process of sifting through article titles, abstracts and keywords ('media,' 'journalism,' 'broadcasting' and so forth) in order to create a sample. As a result of this process, a total of $(n=) 376$ articles across the eight featured titles were deemed eligible for analysis. 
We then developed data charts for each article, based on seven descriptive codes: 1) the topic(s) addressed in the article; 2) the year(s) in which data were collected; 3) method of data collection and analysis; 4) media genre (e.g. television broadcast, newspaper, etc.); 5) summary of argument; 6) best practice advocations/discussions; and 7) recommendations. While these descriptive codes each promised to produce different lines of inquiry depending on our findings, our analysis for the purposes of this article focused on: (1) the number of articles that included 'best practice discussions' or 'recommendations', and (2) the types of 'best practice advocations/discussions' and 'recommendations.' What followed was a process of individually reading, coding and categorizing each of these articles, all the while discussing and refining the details of the codes and contemplating the emergence of themes within our research group. Initially, two members of the research team led the task of coding these articles and interpreting the findings. After the conclusion of that analysis, a further member revisited the articles and repeated the coding process for purposes of reliability. During the entire process, regular meetings were held with all four team members to discuss coding issues and to address discrepancies.

We defined 'best practice' advocations as comments or discussions aimed towards journalists and journalism that advise on how issues identified in their coverage might be avoided, developed, amplified or reworked in future. This definition was necessarily vague, and our inquiry accordingly inductive in nature, as we did not have agreed-upon criteria for what constitutes 'good' (sports) journalism to readily apply. Moreover, the potentially rigid 'application of criteria' to these articles was not attuned to our aim of pursuing 'good' journalism as a question.

That said, certain definitional distinctions emerged from our coding. Initially, we worked from the most encompassing criteria available - including any reference or allusion to best practice. However, in the final analysis, this proved too broad and ambiguous - and not helpful for identifying practical 'best practice' 
suggestions, or demonstrating the extent to which sociologists of sport are prioritizing engagement with specific questions about how journalistic practice might be improved. After all, virtually any critical analysis could essentially be read as implying that sports journalists should avoid producing problematic content (i.e., a critique of xenophobic media coverage implies that media coverage should not be xenophobic). In the end, and instead, we sought out explicit directives for individual journalists and sports media as an institution and a profession.

We also drew a distinction between the best practice 'advocations' we define above, and 'recommendations'. Recommendations we took to mean any suggestion made to those who are positioned to effect change or further a cause within the given circumstances of a study, excluding sports journalists (as these would be included as best practice advocations). While some recommendations were aimed towards athletes, supporters, community workers, politicians, or others with a clear responsibility or interest in the matter under study, the majority were directed 'internally' towards researchers who may continue to study the topic broadly featured in a particular paper. As we will discuss, and is to be expected given the conventions of academic publishing, there were significantly more recommendations than best practice advocations in our sample. But it was the comments addressed to journalists and sports journalism as a collective that promise to inform the question of 'good' sports journalism pursued here. ${ }^{3}$

Our approach to analysis then, while rigorous in the sense that the criteria for deciding what 'counted' as a type of advocation was decided iteratively through ongoing discussions amongst coders - and through the introduction of a final coder who was not involved in the initial discussions to 'recode' the data - we do not claim reliability and validity according to the standards of quantitative content analysis. That is to say, and while our approach resembled in its early stages quantitative content analysis as we individually and then collectively defined broad categories for analysis - in the final instance we were concerned with a set of themes 
or 'types' of advocations, and with attaining a sense of how often (and what) advocations were offered. In this

way, our analysis was 'thematic' and qualitative - as the range comments and recommendations included in the identified articles were read and re-read, with an interest in how they pertained to 'quality' sports journalism (see Braun and Clarke (2006) on thematic analysis, Altheide and Schneider (2013) on qualitative content analysis, and Vaismoradi et al., (2013) on bridging thematic analysis and qualitative content analysis). While we do offer one key number in our results section - that is, the number of articles from our entire sample that included 'best practice' advocations according to the definition of an advocation outlined above - the number itself is relevant only in that it suggests that there were 'not many' advocations, just as one studying a set of interviews will indicate whether a theme is dominant, or not.

\section{FINDINGS}

\section{Best Practice Advocations for Sports Journalists and Media: Themes and Preliminary Reflections}

As noted above, perhaps our most striking finding was the frequency with which 'best practice' advocations occurred at all. Within our analysis, 41 of the 376 articles were found to include 'best practice' advocations for, or discussions about, what might constitute 'good' or 'better' sports journalism (9.17\%) This figure sits in stark contrast to the large, persuasive, critical body of knowledge assembled by sociologists of sport examining 'bad' journalistic practice, for which the field is to be commended.

While our discussion in this paper is dedicated to reckoning with possible explanations and implications for this discrepancy, and reflecting on what might be at stake in addressing it - our attention turns, first, to the types and qualities of these advocations. With this in mind, we have identified the following seven advocations (two of which we brought together in our thematic overview, below) that were recurrent among the 41 sampled articles:

- more and/or more appropriately contextualized reporting 
- more critical media work and more balanced, unbiased and neutral reporting

- more equitable coverage of different sports and athletes

- more equitable representation in the newsroom

- more socially responsible and educative coverage

- and journalist reflexivity

These are, of course, broad advocations that are not inherently or coherently linked to one another (e.g., some refer to who should be in the newsroom, and others to the specific types of coverage that are preferable). With this background, we now describe each advocation.

Advocation \#1: More and/or more appropriately contextualized reporting: The need for more contextualized reporting on sport has been reinforced since (at least) Emig's (1986) article on the 'Barriers of Investigative Journalism,' and as recently as Schultz and Sheffer's (2010) claim, coming directly from an established sports journalist, that the prevalence of Twitter "makes it impossible to put stories in larger context" (236).

Context in these articles was perhaps expectedly a fluid and conditional category - a point that became quite evident as we looked more closely at the range of studies that included the advocation for 'more context'. In a study of how former tennis player Arthur Ashe's diagnosis with AIDS was made public through the media, Laucella (2009) contended that the sports media "should strive for in-depth, critical analysis that provides historical context and longstanding significance. Then, the audience receives useful, comprehensive, accurate, objective, and balanced information" (75). In this case, wider context is deemed preferable for somehow 'better' sports journalism. 
Yet there are numerous examples where the limiting of certain contexts is stated as preferable, that is, where a particular widening of the lens is deemed problematic. Mehler's (2008) advocation that journalists avoid conflating sport and war, despite the historical relation between sport and conflict, and between athletic and military training, is a germane example. Elsewhere, in a study of coverage of the 2000 Summer Olympics in Sydney, Wensing and Bruce (2003) offer a nuanced account of how Australian-Aboriginal athlete Cathy Freeman "was marked as female, but this was not a primary framing device. Instead she was represented as an individual (both Aboriginal and female) who could unite a nation, a positioning that set the coverage of Freeman apart from that of other female athletes" (394). Freeman's discursive marking as a women was omitted, or decontextualized, in order to focus on her athletic achievements; but this was part of a wider strategy to invoke her as symbolic of a unified Australia. We say more about these sorts of complexities in our Discussion, but suffice to say here that 'contextualized' coverage appeared as a fluid and ambiguous signifier of 'good' sports reporting.

Advocations \#2 and \#3: 'More critical media work' and 'more balanced, neutral reporting': A tension emerged through our analysis between advocations for, on one hand, 'critical journalism', and on the other hand, 'unbiased journalism'. We place these in tension because the demand for more balanced and neutral coverage is to some extent at odds with the demand for critical media coverage - coverage that takes seriously its educative function and social responsibility. Consider, for example, Clark's (2011) contention that the "hegemonic practices affecting women in South African football need to be challenged through increased unbiased media coverage" (843) and Kian, Vincent and Mondello's (2008) view that media should seek out and provide counter-hegemonic examples as part of its democratic and social remit. In both of these examples, the pursuit of balanced reporting is said to require an imbalanced corrective. This view of 'unbiased' would 
certainly seem to differ from the less politically charged versions of the term referred to in studies of journalistic quality we reviewed earlier in this paper - that imply neutral or non-partisan journalism.

In fact, the pursuit of balance in many instances was, we found, also often closely related to, even interchangeable with, the pursuit of social justice. For example, the fact that Dave Zirin stands out as a 'radical' sports journalist due to his commitment to amplifying marginal and underreported perspectives arguable renders his approach a commitment to unbalanced reporting (see King, 2008). Nonetheless the case for more 'neutral,' 'balanced,' or 'objective' sports media - that aligned with more classical definitions of the terms was made numerous times across our study, and the demand for critical media work was often the other side of the same coin.

Advocation \#4: More equitable coverage of different sports and athletes: In 1984, Rintala and Birrell's study of Young Athlete magazine led them to argue that even though the publication was far more equitable in its coverage of men and women than rival magazines such as Sports Illustrated, stereotypical portrayals of female athletes therein "may serve to limit the attractiveness of sport for some young readers" (246), including boys and men. The corollary was that "[t]hrough a progressive and enlightened approach to women's sports, [Young Athlete] magazine could educate its male readers to appreciate and respect women athletes as they apparently do male athletes" (Rintala and Birrell, 1984, 247). More recently, Vincent and colleagues (2002) found that coverage of male and female sport was reaching more equitable levels in the Centennial Olympic Games, but added the caveat that this likely follows a commercial imperative rather than any adherence to public service or social justice. Other studies either found that coverage of sports and athletes was inequitable along particular axes of identity, or that coverage was improving - but with ongoing cause for concern (Bernstein, 2002). The general consensus was that unequal coverage was less prevalent than it once was, and 
should be continually redressed, although few articles had explicit advice on how exactly this could or should be done (but see Poulton, 2005).

Advocation \#5: Equity in the newsroom: According to a survey of 320 newspapers and sport Web sites undertaken by Lapchick, Moss II, Russell, and Scearce (2011), men comprise 94\% of sports editors, 90\% of assistant sports editors, $89 \%$ of reporters, $90 \%$ of columnists, and $84 \%$ of copy editors/designers in the U.S. (cited in Anderson and Kian, 2012). Nylund's (2004) study also found that $80 \%$ of U.S. sports talk radio shows are men. Outlining why this demographic must change, Sabo and colleagues (1996) argue that the "genuine empowerment of racial and ethnic minorities in sports media would more fully draw on their journalistic, production, and management skills as well as their athletic abilities" (19). Howe (2008) makes a similarly compelling case for the greater representation of current and former athletes with a disability in Paralympic sports media through his ethnography of the 2004 Paralympic Games newsroom. He does this by demonstrating the problematic effects of coverage lead by the current, able-bodied majority.

But attempts to move towards 'equitable representation' were found elsewhere to be a limited response to problematic sports media coverage. Writing about the presence of two regular female columnists in the magazine Golf Digest, Apostolis and Giles (2011) argued that their inclusion is largely tokenistic as their columns fail to deconstruct the gender binary or address intersecting forms of oppression within golf. As they state: "Therefore, we show that Golf Digest's attempts to include women often act to reinforce dominant ideologies of gender, sexuality, race, and class supported by the dominant position of heterosexual, upperclass, white men" (235).

There is a great deal more that could be said here about the adequacy of addressing newsroom representation on the basis of markers of identity, especially insofar as this could have the performative, troublesome, and in a sense ironic effect of essentializing and reinscribing those markers (e.g., the presence of 
a 'Latino voice' on an otherwise conservative broadcasting network does not, of course, necessarily address the problems with the network or the representation of Latinos in sport). Suffice it to say here that equitable representation of sports journalists was generally regarded as a requisite for 'better' sports journalism, but offers no guarantees towards this end.

Advocation \#6: More socially responsible and educative coverage: Bernstein (2002) is unequivocal in stating that "the media, including commercial television, should assume (at the very least some) social responsibility" (116). Others also echoed the view that "media are vital in maintaining a free and democratic society" (Laucella, 2009: 75). This democratic function of media was often polarized against a prevailing commercial imperative that overwhelmingly dictates the decisions and practices of (sports) media and the societies of which they are constituent and constitutive. One specific example comes from a study by Boykoff and Yasuoka (2014) in which they commend the representation of activists in media coverage of the Winter Olympics in Sochi:

Activist grievances were given significant space, with the Activism Frame appearing in more than a third of the articles. This level of coverage is a rarity in research that assesses media coverage of activists and their ideas. (2014: 45)

Insofar as socially responsible and educative coverage means representing multiple viewpoints, Boykoff and Yasuoka observe a trend in democratized media coverage about the Sochi Games that they claim gained initial momentum in coverage of the London 2012 Summer Olympic Games.

An interesting caveat that breaches the prevailing binary between democratic and commerciallyoriented coverage comes from Hardin et al. (2009), who suggest that "as young sportswriters move into the craft and seek to differentiate themselves from the fan-as-expert, sportainment model, they may find that the most powerful way to make their work relevant, which capitalizes on their professional and ethical training, is 
in a public-service approach to sports coverage" (336). In other words, these authors speculate that while the public service function and democratic responsibility of (sports) media is generally seen in opposition to its prevailing economic rationality, a public-service approach might help secure and develop journalistic careers within the current marketplace, via differentiation from the established 'old boys' network and from the twentyfirst century prevalence of 'fans-as-experts.'

Advocation \#7: More reflexive reporting: Finally, the importance of journalist reflexivity was alluded to in a few articles. Poulton (2005), in one of the most comprehensive discussions of best practice found in our sample, argued that balanced reporting necessarily "involves a degree of reflexivity and circumspection" (42) among journalists. From his study of pervasive violent metaphors in the sports coverage of New Zealand's newspapers, Holt (2000) concluded that 'the description of sporting teams' encounters as 'battles', 'victories', 'defeats' and so forth has long been so commonplace as to be quite 'unmetaphorical' in the average reader's consciousness, although occasionally one finds a journalist of some discrimination drawing direct attention to this phenomenon through punctuation, as in the following NZH headline: '76- Year "War" on Field' (93). This grammatical 'drawing of attention' to ethically and politically dubious choices made in one's own reporting is not a particularly high degree of reflexivity, but it could be seen to represent an instance of at least 'better' sports journalism compared to unreflexively or deliberately sensationalist reporting.

\section{DISCUSSION}

\section{Why Are There So Few Advocations for 'Better Journalism' - and Why So Little Attention to, or Critical Engagement with, the Advocations That Are Offered?}

To reiterate, perhaps more significant a finding than the content of the advocations identified across our sample is the number of articles from which they were drawn, and the amount of attention they were generally afforded. Just under $10 \%$ of the sampled articles explicitly advised on what a 'better' sport journalism 
might look like and how it could be enacted by journalists. Moreover, and with some exceptions (such as Poulton, 2005), most of the advocations collated above are limited to one or two sentences, or on occasion short passages, rather than fully-fledged discussions. And, notwithstanding the important contributions found within those 41 articles, this has not led to a sustained theoretical attempt to define or work towards 'better' or even 'excellent' sports journalism. Why?

It is important to first confront a fairly obvious reality. Sociologists of sport keep doing critical research on sports journalism because sport media, via journalists, keeps producing coverage that demands critique. Implicit to this is the continued recognition of the power and influence of media to not only reflect, but to contour and effect public. Our study suggests that examples of 'bad' sports journalistic practice have been remarkably durable and consistent over the past thirty years, and that those who study sports media have therefore: a) remained closely attuned to the issues associated with and arising from this 'bad' journalism and; b) not recorded or effected a significant shift in the overall quality of reporting. ${ }^{4}$

This justification for continually researching and critiquing sports media therefore has its merits insofar as empirical observation warrants and produces ongoing demand for (critical) scholarly inquiry; sports journalists keep writing and broadcasting (problematically) so we must keep writing (reactively)! But this does not in itself explain the disparity between the many critical analyses and relatively few best practice examples and discussions. We now turn focus on the question of why there might be such a disparity between critical analysis of 'bad' journalism and advocations for better journalistic practice.

Social Theory, Agency and the Role of the Journalist: Theories are not only frameworks with which to explain phenomena such as sports media coverage, but generative tools in disentangling and (re)presenting that coverage in scholarly research (Law, 2004). Theory helps craft the phenomena to which it is addressed, and enacts the conditions of possibility for what will likely be said about, in this case, sports media coverage. It 
follows then that some theoretical and disciplinary perspectives catalyze explanations that may not afford journalists an agentic status in processes of sports media content production and dissemination.

For example, in a study published in the IRSS, Hills and Kennedy (2006) identified the positive development of less oppressive mediations of tennis's Wimbledon Championships arising from the globalization, or 'deterritorialization,' of the (in)famously exclusive Wimbledon brand. “Through the analysis of UK and US media broadcasts and reports," these authors argue that "Wimbledon's legacy of exclusivity predicated on the basis of nation, class, gender, and race is destabilized through this process" of deterritorialization (434). Deterritorialization - a cultural-technological process that reconfigures meanings over time and space - is said to inadvertently enact a kind of broadcasting 'good practice' by fracturing the longstanding modes of exclusion synonymous with Wimbledon. Crudely put, the technological advent of international broadcasting allows for the reframing of local meanings in accordance with national and cultural tastes and traditions (see Silk and Andrews, 2001). The rupturing of oppressive exclusivity in Wimbledon's culturally and historically inflected space through broadcasting in the US is framed not as an outcome of journalistic intent, but as the consequence of the postmodern trans-cultural deterritorialization of established meanings. Perhaps because this was inadvertent, and suggested to be largely unanchored from the specific actions of individual journalists and newsroom cultures, there are no guidelines offered for how journalists and media more broadly might do a 'better' job.

By comparison, an article published in Men and Masculinities (and that thereby fell outside of our sample) by Anderson and Kian (2012) argued that while the male, heterosexual majority working in the field of sports journalism have traditionally adhered to and so reified a hegemonically masculine social script, recent reports on concussion in the National Football League suggest "a crack in this hegemonic system" (153). These authors highlight instances of 'better' sports journalism among the North American print media that are 
sensitive to the welfare of athletes, rather than valorizing the 'glorious sacrifice' of one's (neurological) health in pursuit of sporting success. This positive shift is theorized through Anderson's (2009) notion of 'inclusive masculinities,' and the implication is that broader social change in understandings of gender identity have brought about this shift in reporting - a change that finds its expression in media rather than being instigated through 'better' journalistic practice. The relevant point is that 'better' reporting on concussion is seen to reflect a cultural shift in expressions of masculinity, leaving the concomitant shift in the standard of reporting itself comparatively under-investigated.

While there are notable differences between the analyses offered by Hills and Kennedy and Anderson and Kian respectively, they share common ground in theorizing positive changes in sports media stemming from processes that transcend the newsroom, rather than changes activated by those within the domain of sports journalism. We could posit a 'sliding scale' of sorts, given that in Hills and Kennedy's study globalization is the cause of social change and journalistic practice is therefore not considered, whereas Anderson and Kian do account for specific journalists, even if they are implied to be conduits for broader expressions of and changes in social identity.

Our sample did include research which placed greater emphasis on the role played by journalists in producing media, even in critiquing the cultural and institutional constraints that contour journalistic labour. Howe's (2008) ethnographic study of Paralympic journalism at the 2004 Athens Games investigated "the role played by the print media in constructing an image of the Paralympic Games" (135). His fieldwork enabled him to demonstrate how the content of print media is contested and shaped through the micro-politics of the newsroom, where 'positive' and 'celebratory' materials such as motivational athlete quotes and heroic biographies are distributed to journalists through governing bodies via press officers, thereby sustaining an unreservedly positive image of their organization and the focal event. This is problematic on several levels, not 
least due to the fact that 'able-bodied' journalists and press officers make up the vast majority in the Paralympic newsroom. Consequently, "print journalism output is largely devoid of the culture of Paralympic sport," and issues and details specific to the Paralympic community (such as the relationship between disability classifications and the structure of different events) are thereby lacking in most coverage. Howe's study is significant because, notwithstanding the influence of wider discourses concerning sport for athletes with a disability - including the often patronizing narrative that tends to celebrate overcoming adversity ahead of competition, professionalism and athletic prowess - the newsroom and the individuals and institutions that constitute its workings are recognized as active, despite the many constraints they face, in shaping the media message.

These three studies, via differing theoretical perspectives, methodological approaches and political objectives, each demonstrate the range of influences acting upon the production of sports media content. Whether it is due to the overriding, trans-cultural deterritorialization of sports broadcasting, broader changes in expressions of social identity, or the cultural, economic and institutional constraints placed on the labour and output of individual journalists, all three articles show how journalistic content is contoured, for better and worse. Yet none of the three advise on how the specifics of journalistic practice could be improved, either in practical or theoretical terms.

And this is perhaps for good, sociological reasons. That is to say, some scholars might see it as superficial to advise on better journalistic practice when it is systems, structures, and logics such as capitalism, patriarchy or heteronormativity that incubate and reproduce problematic ideas and assumptions, and that are in turn perpetuated and reified through sports media. These are plausible sociological reservations that are sensitive to the wider socio-historical structures through which particular issues are (re)produced. In an important sense, then, it might be considered somewhat a-sociological to advise on the individual craft of the 
journalist when the prevailing point is that the content produced by journalists is itself product and producer of wider social, cultural, historical, economic and political conditions, which are what demand greater scrutiny. Thus Hills and Kennedy are primarily concerned with how information flows and how it is shaped as it moves through transnational communication channels; Anderson and Kian with how changes in dominant modes of masculinity might be evidenced via sports media coverage; and Howe with the institutional and associated commercial constraints placed upon Paralympic reporting.

The significant discrepancy in our findings, then, is at least partially attributable to the tendency, and indeed the strength, of the sociology of sport in situating sports media coverage in its wider contexts. But there are other possibilities too for the discrepancy in our data, including the perceived capacities and responsibilities of a relatively small academic field of study to actually affect any significant change in the world of sport media - a point we take up next.

Critical Sports Media (Research) as Public Pedagogy: Critical sports media research is often considered an intervention, or a form of pedagogy, in its own right. The aim and responsibility of the researcher(s) is thus not to directly affect the practice of sports journalism per se, but to produce analyses of sports media coverage that are contextualized in order to show the conditions in and through which (often 'bad') journalism is produced, and in so doing produce something 'new.' Scholars and students are accordingly exposed to and informed by the explanations and critiques advanced through this scholarship. This likely forms at least part of the rationale for many of the critical studies of sports media in our sample that did not go on to advise on best journalistic practice.

An example of critical sports media research with an explicitly pedagogical and political aim comes via Silk and Falcous' (2005) study of American (sporting) nationalisms. The authors demonstrate how "the media operated as a conduit for the powerful symbolic revision of the post-9/11 American identity" (455) 
following the events of September 11th, 2001. They conclude by reaffirming the need to, in the parlance of cultural studies, 'police the crisis' among (sports) media coverage by "undoing the official pedagogies that circulate in the media, and by offering critical, multivoiced, moral pedagogies of truth that produce justice, peace, empowerment, and freedom" (465). Thus a new pedagogy is created in the spaces opened up through critique of the dominant media frame.

What is less clear, not just in Silk and Falcous' study but in the vast majority of the sampled articles, is how 'better' frames, including 'critical, multivoiced, moral pedagogies,' are hoped to become manifest. A common justification for critiquing sports media coverage is that it is a powerful form of public pedagogy, and much scholarly attention is devoted to the workings of, to borrow again from Silk and Falcous, 'undoing official pedagogies that circulate in the media.' Yet the rationale for researching media in the first place is undermined if it is seen as only a conduit for ideological and political interests such as those of the Murdoch-owned FOX News corporation and Sky Sports enterprise. For it would follow that only significant, even transformative developments in society would produce 'better' reporting. The paradox is that the power of media is at once acutely recognized in sports media research by way of a rationale for that research, and yet often explained away as something else - such as the power of neoliberalism, patriarchy, heteronormativity, and so forth. Consequently, if a sports journalist looking to improve their craft were to consult the sociology of sport in order to seek out instances of 'better' practice in spite of the varied technological, cultural, political, economic, and institutional forces that contour their labor, then they would glean far more about what not to do, among a reiteration of what inhibits their work, than anything affirmative.

The issue is not that research on sports media critically attends to deleterious media coverage and thereby instantiates its own intervention; this is to be commended. It is, we would suggest, a broader and longstanding ambiguity in the relationship between the university, academics and academic fields of study, 
and the societies they write in, of, and for. In the past decade, sociologists of sport have followed a trend set in the 'parent discipline' by attending closely to the question of public engagement (e.g., Bairner, 2009). One of the questions raised by this literature is the extent to which public engagement through sociology (see Burawoy, 2005 ) is possible and desirable for fields of academic study and scholars therein. Some have argued that public engagement is imperative for a field to fulfil its obligations as (in most cases) public, partially tax-funded institutions; others believe that such exposure to the world 'outside' of the university could be detrimental to the integrity of research and respective fields of study, perhaps by pandering too closely to the needs of particular industries or over-simplifying or even depoliticizing complex and controversial ideas.

From our findings we might cautiously infer that the latter skeptical and pessimistic view is more prevalent among sociologically-informed scholarship on sports media. It may well be the case that many sociologists of sport do not expect that their research will have any direct impact on, or will ever be read by, sports journalists or those responsible for what happens in newsrooms or broadcasting suites. And, given that academic research is largely inaccessible to those who do have access to university libraries (the main channel through which to access scholarly journals outside of expensive subscription fees for individual titles and articles), there is good reason to suspect as much. The fact is that there is no clear pathway between sports media and sports media research, and our study is filled with examples of all the obstructions that would hinder such a pathway, and comparatively little consideration of what it might look like, what its establishment might entail, or how exactly all parties could benefit.

It is of course far too simplistic to imagine that theorizing better sports journalism would, as if by osmosis, affect better journalistic practice. But does that mean that sociologists of sport should not be looking to render their far-reaching critiques of sports coverage into something more affirmative, to which journalists might contribute, learn from, or at least dispute? After all, we have seen these benefits flow in the other 
direction: ethnographers of sports media (e.g. MacNeill, Donnelly and Knight, 2001; Howe, 2008; Lowes, 1999) have returned a wealth of insights about the mechanics of newsrooms and broadcasting studios to the sociology of sport. Perhaps it is a timely, if not belated endeavor to write towards and even for a sports journalism that is, at the very least, informed by the sociology of sport. What would it look like, and how might it be informed by - without compromising - our critical efforts to date?

\section{So What is 'Good' Sports Journalism? Problems of Theory and Practice}

We conclude our analysis by looking at two revealing exceptions to the trends we have emphasized: an article by Richard King that valorizes a particular journalist (Dave Zirin) for doing what David Rowe (2007) might call "problem-oriented journalism" (p. 389); and a paper (from outside our sample) by Pate and Hardin (2013) entitled "Best Practices for Media Coverage of Athletes with Disabilities" that is distinguished in offering specific guidelines for sports journalists.

First, Pate and Hardin's article features a discussion of ways that athletes with disabilities are commonly and traditionally reported on - noting that journalists frequently emphasize athletes' disabilities and deemphasize other storylines, and in other cases offer what has been termed a 'supercrip' narrative about the athlete heroically overcoming the barriers posed by a disability. They go on, however, to offer concrete suggestions for improving coverage of athletes with disabilities. They advocate, for example, for the use of 'person first' (i.e., not disability first) language, and recommend coverage that is not strictly focused on athletes' disabilities.

Pate and Hardin recognize, as did MacNeill (1998) and Horky and Stelzner (2013), that the meanings ascribed to language and media portrayals of all kinds are context-dependent and will shift over time. Yet they do not see this as a reason to avoid offering suggestions for what they see as uninformed and irresponsible portrayals of athletes with disabilities. On the contrary, they assert that "being aware of the evolving acceptance 
of labels should be treated with the same diligence journalists place on fact checking and source credibility, two core journalistic practices and characteristics that often change over time" (Pate and Hardin, 2013: 366). Their paper is thus a rare example of research that features specific guidelines for journalists covering sport i.e., guidelines offered by scholars (i.e., Pate and Hardin) who critically study sport. ${ }^{5}$

Second, an article drawn from within our sample (2008) by Richard King entitled "Toward a Radical Sports Journalism: An Interview with Dave Zirin.” Zirin’s journalism, lauded by sociologists of sport for some years now, is defined as radical because so few other sport journalists are deemed to have "challenged the mores of the profession nor openly pressed for a kind of reporting that at once engages with the politics of sport and promotes social justice” (333). In King's appraisal, Zirin:

concerns himself with labor relations and the corporatization of sport; the prejudices and biases of fans and sportswriters, especially racism, homophobia, and sexism; and the spectacles of nationalism. Whereas the mainstream media castigate athletes, often inciting moral panics and social outrage, Zirin champions the humanness and potential of players. In fact, Zirin often focuses on the athletes who resist, transgress, or reject prevailing norms and dominant ideologies. He takes hope in the resistance of past and present players, often calling out superstars who remain silent or compliant, while complicating the comfortable declarations of others. At the same time, he defends players, like Barry Bonds, Sheryl Swoopes, and Michael Vick, who become easy targets of scorn (334).

While we would argue that sport and sports media are overall better for Zirin, and that the sociology of sport is richer for King's article - it is perhaps revealing that King's paper is presented as an interview, as opposed to any kind of analysis. That is to say, rather than situate Zirin's journalism in any kind of existing model, or use it as empirical material with which to work towards such a vision for 'better' sports journalistic 
practice, it is presented as an anomalous example of 'radical' sports journalism. What exactly we are supposed to learn from Zirin is left open to the reader to interpret, and theoretically untapped.

In accordance with the foregoing analysis, we venture that this framing of Zirin's work as radical or anomalous is actually a consequence of the prolonged oversight we have sought to highlight. Simply put, we do not know what to do with it, except to celebrate it (and him) in splendid isolation. More pointedly, we have scarcely begun to develop (or indeed borrow) the tools, models or the networks needed to replicate it among students and scholars alike. So even though it might appear that in continually producing similar critiques of sports media, sociologists of sport are conforming to the clichéd definition of 'insanity' often attributed to Einstein, the explanation might actually be far more systemic than that. There is a continuing demand for critical work on sports media, but it is also high time that instances of 'good' sports journalism be afforded the theoretical and empirical attention long granted to their 'bad' journalistic counterparts.

\section{CONCLUSION}

There is no consensus in twenty-first century journalism about what constitutes quality reporting. Not only are the concepts being tested and deployed amid a shifting political-economy which conditions and privileges certain definitions of quality - such as how frequently an article has been clicked, liked, commented on, shared, syndicated and so forth - but the ground of the twentieth century media industries was never so stable as to lend itself to a universally adhered to notion of 'excellence' in journalism. For example, as noted in our findings, sports media scholars have made numerous calls for either balanced, neutral or objective reporting, as well as more critical, social justice-oriented coverage of sports. Yet objectivity has never been a stable referent for quality in journalism. Journalism scholar Stephen Ward (2004: 10) has written of how the "doctrine of objectivity" was invented by newspapers in the early twentieth century in order to "assure the 
public that its news was factual and fair." Objectivity derives from conversations about ethics derived from Ancient Greece, and gains currency in journalism as a way of discussing the relationship between media and democracy. Its flaws have been the subject of a great deal of discussion in 1980s and 1990s across the social and natural sciences, yet the concept persists, as our study indicates, as a category for assessing impartial reporting.

The concept of transparency, which emphasizes openness and accountability rather than impartiality, has recently become used in journalism to understand and acknowledge how certain news items, narratives and information sources become prominent (see Karlsson, 2010). Yet in sports journalism, objectivity still prevails. A series of sports journalism textbooks (cited earlier in this paper), consulted as part of our broader efforts to pursue the question of 'good' sports journalism, each lead with more or less nuanced versions of objectivity as a marker of journalistic quality. Moreover, the findings of this study show that objectivity is at once called for and contested by those sports media scholars who have written towards 'good' sports journalism.

That there is no consensus on what constitutes quality journalism, sporting or otherwise, means that sociologists of sport might yet have some influence in helping craft a definition that eschews the many problems identified with sports media across five decades of research. In this spirit, we conclude with a couple of short suggestions for future research that could implicate the sociology of sport in this timely process of thinking towards 'excellent' journalism, without compromising its critical, political or sociological tendencies.

The first is to encourage a move away from a 'critique only' orientation in the study of sports media content. Here is Lawrence Wenner, assessing the study of 'communication and sport' in launching the journal of that name, and calling for a "narrative ethics" that transcends critique. Of prospective research on communication and sport, he writes: 
Certainly, there should be much on its agenda beyond my core concerns over the "dirtiness" of it all. Foremost, and this is an essential deficiency in my own "dirty agenda" about sport-referential narratives, we need to move, fast and hard, beyond textual analysis and criticism. As I have lamented many times (Wenner, 1998c, 2006), we tend to do the "easy stuff” first, and analysis of texts is not enough to get a good read on audience experience on one hand, and the dynamics of media sport institutions on the other. It has been most disappointing how little research has been done on the institutional and organizational dynamics that shape media and sport. (p. 195)

To this we would add that textual analysis does not lend itself to best practice suggestions since it focusses on the product, and not the production of content. Several of the studies that we identified here as offering a 'best practice' advocation were drawn from research that dealt with more than content. Howe's (2008) aforediscussed study of the Paralympic newsroom, for example, offered a multilayered ethnographic account of how stories are coded with different interests, beliefs and intentions before they make the back pages. Fetishizing sports media content - that is, analyzing it apart from its conditions of production - often meets its political and ethical limits in critique of that content. Tracing the production and consumption of stories, from breaking to the evaluation of comments, is no doubt a more labour-intensive means of studying sports media, often requiring access to news desks, and the consent of journalists, editors, and others involved in bringing stories to print, television and online formats. But it also promises more comprehensive accounts of how sports media content is mobilized as content, by tracing the labour that goes into their production, representation, and consumption. Opportunities to do so are wider given that sport is produced and consumed with mobile/cell phones, laptops and tablets, digital radio and podcasts, in concert with subscription and terrestrial television and newspapers (Dart, 2014). 
The invocation of journalistic gatekeepers brings us to our second suggestion: that less emphasis be placed on what divides those who study sports media. In the making of this study we have encountered many attempts to establish the boundaries of the sociology of sport - of its purview as regards being able to say anything affirmative about the 'doing' of sports journalism. We suggest that whether these claims are true is of less interest and import than what kind of engagements with sports media they encourage and discourage. We have also become increasingly aware of the sociology of sport as a product of many different influences, from a whole host of social scientific disciplines and fields to the contributions of sports professionals, including academics who are also current or former (sports) journalists. While we were tasked with drawing boundaries around the sociology of sport and its contributions to sports media research in order to develop a sample for this study, oftentimes this only served to illustrate the eclecticism of the field.

It was rare for our study to be furthered by the enforcing of these borders; more productive by far was focussing on the great range of commonalities between, say, the sociology of sport and communications as pertains the study of sports media. To an outsider, including journalists who do not work in these scholarly areas, the differences might even be negligible. The complexity and changing shape of media industries far outpaces any attempts to delegate expertise; meanwhile the issues that have inspired the foundation of both fields remain pressing.

Finally, we posit that positive change is more likely to come from the education of tomorrow's sports journalists, and collaborations with current ones, than from critiquing the institutionalized practices of reporters and broadcasters who already have hundreds if not thousands of critics below the line. Here it is easy to see why those in communications and broadcast journalism departments - such as Marie Hardin, Rob Steen, Ted Kian and Welch Suggs - are especially well-positioned to affect practice through training. Yet sociologists of sport - as specialists in the study of sport and social issues, and long-time commentators on 
and researchers of sports media - are also well-positioned to contribute to a profession (i.e., journalism) that has demonstrated a need and interest in more nuanced approaches to covering sport-related social issues. Our call, again, is for a generative project that would animate sociological research designed, even in part, to inform journalistic practice. What would it look like? With whom would it best be undertaken? And through what mediums, formats, narrative forms, and institutional structures would it be most effective?

\section{NOTES}

${ }^{1}$ Excluded here, for example, were articles concerned exclusively with advertising, film, and the use of new media that was not relevant to journalistic practice

2 The International Review for the Sociology of Sport, established in 1966, was the oldest title in our sample, with the 2008 founding of the International Journal of Sport Communication making it the newest. The Journal of Sport and Social Issues (est. 1977), Sociology of Sport Journal (1984), Olympika (1992), Sport in Society (1998), Soccer and Society (2000), and the International Journal of Sport Communication (2008), make up our sample. In cumulative total, our study covered 166 years of sociology of sport publications, beginning with Milshteyn and Molchanov (1976) article published in the IRSS as 'The Shaping of Public Opinion Regarding Sport by the Mass Media as a Factor Promoting International Understanding.' The journal Sport and Communication was founded in 2013 and so while clearly relevant to our study, not included in our sample.

${ }^{3}$ One important caveat to stress is that our study of sport journalism is in many respects an Anglicized one. That is to say, while many of the articles under study included examinations of coverage of events in varying parts of the world and on occasion made comparisons between coverage in different countries, it would be remiss to universalize our contentions to relatable but not assimilable developments in the sociologies of 
sport in Asia and Latin America, for instance. Insofar as we are presenting a review of research on sport journalism in the sociology of sport field, our abridged history focuses largely on research emerging from Europe, North America and Australasia.

${ }^{4}$ Among the exceptions is Alina Bernstein's (2002) article assessing changes in media representations of women and/in sport. Her study suggests that while the amount of coverage afforded to women's sport in mainstream media increased through to the late 1990s, and women's participation in sport has generally increased in Western societies since the 1970s, representations of women's sport, and women in sport, are resiliently gendered, derogatory, and disproportionate to men's sports.

${ }^{5}$ In saying this, we recognize that Pate and Hardin's suggestions were informed by a guide for journalists produced by the International Paralympic Committee.

\section{REFERENCES}

Altheide D and Schneider C (2013). Qualitative Media Analysis (Vol. 38). Sage.

Anderson E (2009) Inclusive Masculinity: The Changing Nature of Masculinities. New York: Routledge.

Anderson E and Kian EM (2012) Examining media contestation of masculinity and head trauma in the National Football League. Men and Masculinities 15: 152-173.

Andrews P (2015) Sports Journalism: A Practical Introduction (second edition). London: Sage.

Apostolis N and Giles AR (2011) Portrayals of women golfers in the 2008 issues of Golf Digest. Sociology of Sport Journal 28(2): 226-238.

Bairner A (2009) Sport, intellectuals and public sociology: obstacles and opportunities. International Review for the Sociology of Sport 44(2-3): 115-129.

Bernstein A (2002) Meeting the industry: an interview with Alex Gilady. Sport in Society 5(3): 115-138. 
Bogart L (2004) Reflections on content quality in newspapers. Newspaper Research Journal 25(1): 40-53.

Boykoff J and Yasuoka M (2014) Media Coverage of the 2014 Winter Alympics in Sochi, Russia: Putin, Politics, and Pussy Riot. OLYMPIKA, 23, 27-55.

Boyle R (2006) Sports Journalism: Context and Issues. London: Sage.

Braun V and Clarke V (2006) Using thematic analysis in psychology. Qualitative Research in Psychology 3(2): 77-101.

Bruce T (2015) Assessing the sociology of sport: On media and representations of sportswomen. International Review for the Sociology of Sport 50(4-5): 380-384.

Burawoy M (2005) For public sociology. American Sociological Review 70(1): 4-28.

Clark C (2011) Leading or losing? Women challenging male hegemony in South African football and the FIFA World Cup. Soccer \& Society 12(6): 834-849.

Cottle S (2006) Mediatized Conflict: Developments in Media and Conflict Studies. Maidenhead: Open University Press.

Dart J (2014) New media, professional sport and political economy. Journal of Sport and Social Issues 38(6): 528-547.

Deuze M (2005) What is journalism? Professional identity and ideology of journalists reconsidered. Journalism 6(4): 442-464.

Donnelly P (2011) Taking Sport Seriously: Social Issues in Canadian Sport. Toronto: Thompson Educational.

Emig J (1986) Barriers of investigative sports journalism: an empirical inquiry into the conditions of information transmission. International Review for the Sociology of Sport 21(2-3): 113-129.

Farrington, N, Kilvington, D, Price, J and Saeed A (2012) Race, racism and sports journalism. London: Routledge. 
Gisondi J (2011) Field guide to covering sports. Washington DC: CQ Press.

Hardin, M, Dodd, J and Lauffer, K (2006) Passing it on: The reinforcement of male hegemony in sports journalism textbooks. Mass Communication \& Society 9(4): 429-446.

Hardin M, Simpson, S, Whiteside E. and Garris K (2007) The gender war in US sport: Winners and losers in news coverage of Title IX. Mass communication \& society 10(2): 211-233.

Hardin, M, Zhong B and Whiteside E (2009) Sports coverage: “toy department” or public-service journalism? The relationship between reporters' ethics and attitudes toward the profession. International Journal of Sport Communication 2(3): 319-339.

Horky T and Nieland JU (2013) International Sports Press Survey 2011 (Vol. 5). BoD-Books on Demand.

Hills L and Kennedy E (2006) Space invaders at Wimbledon: televised sport and deterritorialization. Sociology of Sport Journal 23: 419-437.

Holt R (2000) The discourse ethics of sports print journalism. Culture, Sport, Society: Cultures, Commerce, Media, Politics 3(3): 88-103.

Horky T and Stelzner B (2013) Sports reporting and journalistic principles. In: Pederson P (ed) Routledge Handbook of Sport Communication. New York: Routledge, pp. 118-127.

Howe PD (2008) From inside the newsroom: Paralympic media and the 'production' of elite disability. International Review for the Sociology of Sport 43(2): 135-150.

Hutchins B and Rowe D (2013) Digital media and sport: Technology, power and culture in the network society (vol. 51). New York: Routledge.

Kaplan S (2016) SB Nation publishes, then deletes, 'complete failure' of story about ex-cop, football player turned serial rapist. The Washington Post, 18 February, 16. Available at: www.washingtonpost.com/news/morning-mix/wp/2016/02/18/sb-nation-publishes-then-deletes- 
complete-failure-of-a-story-about-ex-okla-cop-who-was-convicted-of-raping-8-women/ (accessed 24 March 2016).

Karlsson M 2010 “Rituals of Transparency,” Journalism Studies 11(4): 535-545.

Kian EM, Vincent J and Mondello MJ (2008) Masculine hegemonic hoops: An analysis of media coverage in March madness. Sociology of Sport Journal 25(2): 223-242.

Kim KH and Meyer P (2005) Survey yields five factors of newspaper quality. Newspaper Research Journal 26(1): 6-15.

King CR (2008) Toward a radical sport journalism: an interview with Dave Zirin. Journal of Sport \& Social Issues 32(4): 333-344.

Lapchick RA, Moss II A, Russell C and Scearce R (2011) The 2010-11 Associated Press Sports Editors racial and gender report card. Report, University of Central Florida, Institute for Diversity and Ethics in Sport. Available at:

www.tidesport.org/RGRC/2011/2011_APSE_RGRC_FINAL.pdf?page=lapchick/110517 (accessed 8 August 2011).

Laucella PC (2009) Arthur Ashe, privacy, and the media: an analysis of newspaper journalists' coverage of Ashe's AIDS announcement. International Journal of Sport Communication 2(1): 56-80.

Law J (2004) After Method: Mess in Social Science Research. London: Routledge.

Lowes M (1999). Inside the Sports Pages: Work Routines, Professional Ideologies, and the Manufacture of Sports News. Toronto: University of Toronto Press.

Lynch J (2012) Peace journalism works. The Peace Journalist 1(2): 3-4.

Lynch J and McGoldrick A (2005) Peace Journalism. Gloucestershire: Hawthorn Press.

MacNeill M (1998) Sports journalism, ethics, and Olympic athletes' rights. MediaSport (1998): 100-115. 
MacNeill M, Donnelly P, and Knight G (2001) Corporate training: identity construction, preparation for the Sydney Olympic Games \& relationships between Canadian media, swimmers and sponsors. OLYMPIKA 10: 1-32.

Malcolm D (2012) Sport and Sociology. London: Routledge.

McPherson BD, Curtis JE and Loy JW (1989) The Social Significance of Sport: An Introduction to the Sociology of Sport. Champaign: Human Kinetics.

Mehler A (2008) Political discourse in football coverage - the cases of Côte d'Ivoire and Ghana. Soccer \& Society 9(1): 96-110.

Milshteyn OA and Molchanov SV (1976) The shaping of public opinion regarding sport by mass media as a factor promoting international understanding. International Review for the Sociology of Sport 11(3): 71-84.

Nohrstedt S and Ottosen R (2011) Peace journalism-critical discourse case study: Media and the plan for Swedish and Norwegian defence cooperation. In: Shaw I, Lynch J and Hackett R (eds) Expanding Peace Journalism: Comparative and Critical Approaches. Sydney: Sydney University Press, pp. 217 238.

Nylund D (2004) When in Rome: heterosexism, homophobia, and sports talk radio. Journal of Sport \& Social Issues 28(2): 136-168.

Oates TP and Pauly J (2007) Sports journalism as moral and ethical discourse. Journal of Mass Media Ethics 22(4): 332-347.

Pate J and Hardin R (2013) Best practices for media coverage of athletes with disabilities: A person-first language approach. In: Pederson P (ed) Routledge Handbook of Sport Communication. New York: Routledge, pp. 359-368. 
Pederson P (ed) (2013) Routledge Handbook of Sport Communication. New York: Routledge.

Poulton E (2005) English media representation of football-related disorder: 'brutal, short-hand and simplifying'? Sport in Society: Cultures, Commerce, Media, Politics 8(1): 27-47.

Rintala J and Birrell S (1984) Fair treatment for the active female: A content analysis of Young Athlete magazine. Sociology of Sport Journal 1(3): 231-250.

Rosen J (2001) What are journalists for? New Haven: Yale University Press.

Rowe D (1992) Modes of sports writing. In: Dahlgren P and Sparks C (eds) Journalism and Popular Culture. London: Sage, pp. 96-112.

Rowe D (2007) Sports journalism still the toy department of the news media? Journalism 8(4): 385-405.

Sabo D, Jansen SC, Tate D, Duncan MC and Leggett S (1996) Televising international sport: race, ethnicity, and nationalistic bias. Journal of Sport \& Social Issues 20(1): 7-21.

Schultz B (2005). Sports media: planning, production, and reporting. Oxford: Elsevier.

Schultz B and Sheffer ML (2010) An exploratory study of how Twitter is affecting sports journalism. International Journal of Sport Communication 3(2): 226-239.

Shapiro I, Albanese P and Doyle L (2006) What makes journalism “excellent”? Criterial identified by judges in two leading awards programs. Canadian Journal of Communication 31(2): 425-445.

Shapiro I (2010) Evaluating journalism: towards an assessment framework for the practice of Journalism. Journalism Practice 4(2): 143-162.

Shapiro I (2014) Why democracies need a functional definition of journalism now more than ever. Journalism Studies 15(5): 555-565.

Silk M and Andrews D (2001) Beyond a boundary: sport, transnational advertising, and the reimagining of national culture. Journal of Sport \& Social Issues 25(2): 180-202. 
Silk M and Falcous M (2005) One day in September / a week in February: mobilizing American (sporting) nationalisms. Sociology of Sport Journal 22(4): 447--471.

Singer JB, Domingo D, Heinonen A, Hermida A, Paulussen S, Quandt T, Reich Z and Vujnovic M (2011) Participatory Journalism: Guarding Open Gates at Online Newspapers. West Sussex: John Wiley \& Sons.

Steen R (2015) Sports journalism: a multimedia primer (Second edition). London: Taylor Francis.

Suggs, D.W. (2015). Tensions in the press box Understanding relationships among sports media and source organizations. Communication \& Sport. Online First at: DOI: 10.1177/2167479515577191

Thussu D (2000) International Communication: Continuity and Change. London: Arnold.

Toney J (2013) Sports journalism: The inside track. London: Bloomsbury.

Toulmin S (1986) The Place of Reason in Ethics. Chicago: University of Chicago Press.

Vaismoradi, M, Turunen, H and Bondas T (2013) Content analysis and thematic analysis: Implications for conducting a qualitative descriptive study. Nursing \& Health sciences, 15(3): 398-405.

Verband Deutscher Sportjournalten (2010) Satzung des Verbandes Deutscher Sportjournalisten e.I/. MannheimzVerband Deutscher Sportjournalisten.

Vincent J, Imwold C, Masemann V and Johnson JT (2002) A comparison of selected 'serious' and 'popular' British, Canadian, and United States newspaper coverage of female and male athletes competing in the centennial Olympic Games: did female athletes receive equitable coverage in the 'Games of the women'? International Review for the Sociology of Sport 37(3-4): 319-335.

Ward S (2004) The invention of journalism ethics. McGill-Queen's University Press.

Wenner L (2013) The mediasport interpellation: Gender, fanship, and consumer culture. Sociology of Sport Journal 30(1): 83-103. 
Wenner L (2013) Reflections on communication and sport: On reading sport and narrative ethics. Communication \& Sport, 1(1/2): 188-199.

Wensing EH and Bruce T (2003) Bending the rules: media representations of gender during an international sporting event. International Review for the Sociology of Sport 38(4): 387-396.

Wright EO (2010) Envisioning Real Utopias (Vol. 98). London: Verso. 